\title{
Microstructure and fracture behavior of friction stir lap welding of dissimilar metals
}

\author{
R.N. Shubhavardhan ${ }^{a^{*}}$ and S. Surendran ${ }^{b}$
}

${ }^{a}$ Department of Mechanical Engineering, University of Saskatchewan, Saskatoon, Canada ${ }^{b}$ Department of Ocean Engineering, Indian Institute of Technology, Madras Chennai, India

\begin{tabular}{|c|c|}
\hline A R T I C L EI N F O & A B S T RACT \\
\hline $\begin{array}{l}\text { Article history: } \\
\text { Received 26 August, } 2017 \\
\text { Accepted 9 December } 2017 \\
\text { Available online } \\
\text { 9 December } 2017 \\
\text { Keywords: } \\
\text { Friction stir lap welding } \\
\text { Aluminum } \\
\text { Steel } \\
\text { Titanium } \\
\text { Intermetallics } \\
\text { Fracture strength }\end{array}$ & $\begin{array}{l}\text { Friction Stir Welding (FSW) is a relatively new solid state joining technique which is used not } \\
\text { only for joining the aluminum and its alloys but also has potential for joining dissimilar } \\
\text { materials with very different physical and mechanical properties which are hard to weld using } \\
\text { conventional fusion welding processes. Tensile shear testing is used to determine the } \\
\text { Mechanical strength of friction stir lap (FSL) welds under static loading, fracture strength } \\
\text { ( } \sigma \text { Lap) corresponding to the maximum load in a test over the sample width is widely used as } \\
\text { the strength value. During friction stir lap welding (FSLW) of dissimilar metals with large } \\
\text { differences in melting temperatures, a metallurgical bond is established through the formation } \\
\text { of interfacial intermetallic compounds. However, as these intermetallic compounds are } \\
\text { generally believed to be brittle with little ductility, they are generally considered to have } \\
\text { detrimental effect on fracture strength. The aim of the present research is to study how the } \\
\text { interface structure is affected by FSW parameters and how the formation of interface structure } \\
\text { affects fracture of Al-Steel and Al-Ti FSL welds. }\end{array}$ \\
\hline
\end{tabular}

(C) 2018 by the authors; licensee Growing Science, Canada.

\section{Introduction}

Friction stir lap welding of dissimilar alloys such as Al-to Al, Al-to-steel, Al-to-Ti or Al-to-Cu is also of enormous significance in many industries and many research activities have been done for investigating such dissimilar weldments (Abdollah-Zadeh et al., 2008; Akbari et al., 2016; Aliha et al., 2016, 2017; Aonuma \& Nakata, 2011; Jiang \& Kovacevic; 2004) In this paper, we focus on an example of friction stir lap welding (FSLW) of one metallic alloy to another with considerably higher melting temperature - FSLW of Al-steel and Al-Ti. It is well known that fusion welding of Al-to-steel and Al$\mathrm{Ti}$ is very challenging (Taban et al., 2010; Liedl et al., 2011). In FS welding of Al-steel and Al-Ti, aided by frictional and deformation heat, metallurgical bond is established through diffusion and

\footnotetext{
* Corresponding author.

E-mail addresses: shr492@mail.usask.ca (R.N. Shubhavardhan) 
subsequent formation of interfacial intermetallic, as indicated in Fig. 1 for FSLW. A metallurgical bond is a condition for a quality joint, although intermetallics are commonly viewed to affect joint strength adversely (Elrefaey et al. 2005; Kimapong \& Watanabe 2005). There have been many studies on FSLW of Al-Steel (Coelho et al. 2008; Elrefaey et al. 2005; Chen \& Nakata 2008; Chen et al. 2008; Movahedi et al., 2011). Early investigation by Elrefaey et al. (2005) on Al-Steel FSLW clearly established that the tool pin slightly $(\sim 0.1 \mathrm{~mm})$ penetrating to steel is a condition for a metallurgical joint to be established at the Al-Steel interface, resulting in a good joint strength. Although detailed quantification was not done in their study, it was clear that the interface region of welds made with pin penetration is a highly irregular structure of mix layers. Coelho et al. (2008) names the irregular interface region as mixed stir zone. The thin layers, significantly less than $0.5 \mu \mathrm{m}$ in thickness are laminated with recrystallized fine grains of $\alpha$-Fe in this mixed stir zone. Kimapong and Watanabe $(2005 \mathrm{a}, \mathrm{b})$ made an attempt to correlate the $\sigma$ Lap to the thickness of the intermetallic layer, under the condition of pin penetration. Their data shows that in general increasing intermetallic compound thickness reduces $\sigma$ Lap, however the meaning of the referred intermetallic thickness is unclear and misleading. In most studies on FSLW of Al-Steel, tensile shear testing has been used for evaluating the joint strength. Kimapong and Watanabe (2005a) reported $\sigma$ Lap values, ranging from $280 \mathrm{~N} / \mathrm{mm}$ to $559 \mathrm{~N} / \mathrm{mm}$ for a wide range of FSLW and pin penetrating conditions. However, the reason is unclear as to why some of their welds displaying severe discontinuity with voids along the interface region, exhibited high values.

Al-Ti FSLW was conducted by Chen and Nakata (2009). Many void defects formed at the side of titanium because of insufficient flow behavior of titanium during FSLW. However, when the pin did not penetrate the titanium plate, the joint exhibited high $\sigma$ Lap value of $469 \mathrm{~N} / \mathrm{mm}$. they also suggested that AlTi3 intermetallic phase formed at the interface region, based on $\mathrm{x}$-ray diffraction patterns obtained from the fracture surfaces of tested samples. However, their results may not be accurate as no visible intermetallic layer can be seen in SEM micrograph of interface region. Chen et al. (2012) conducted detailed quantification was not completed in their study, it can be seen from their micrographs that the interface region of welds is a highly irregular structure of mix layers. Review of literature on other solid-state joining techniques such as diffusion bonding (Wilden \& Bergmann, 2004) and friction welding (Wilden \& Bergmann, 2004; Fuji et al., 1997, 2001, 2004; Robertson \& Schaffer, 2010) shows that TiAl3 intermetallic layer formed at the Al-Ti interfaces. However, the intermetallic layer has been reported to be very thin (less than one micron) due to insufficient thermal energy for intermetallics growth. On the other hand, formation of several micron thick TiAl3 intermetallic layers has been commonly observed in fusion welding of Al-Ti welds (Vaidya et al., 2010; Chen et al., 2011). That is because fusion welding techniques are all conducted at temperatures above the melting point of aluminum, and thus higher peak temperature of welding together with presence of liquid aluminum enhance the diffusion rate of Al-Ti atoms and thus faster growth of intermetallic layer. Therefore, formation of TiAl3 phase at the Al-Ti interface is widely recognized to provide metallurgical bonding in Al-Ti joints. In this paper FSLW of Al-to-steel and Al-Ti, to explain how interface microstructures affect the fracturing process during tensile-shear testing and thus joint strength. A possible control method for producing Al-to-steel and Al-Ti welds for a higher joint strength can then be suggested.

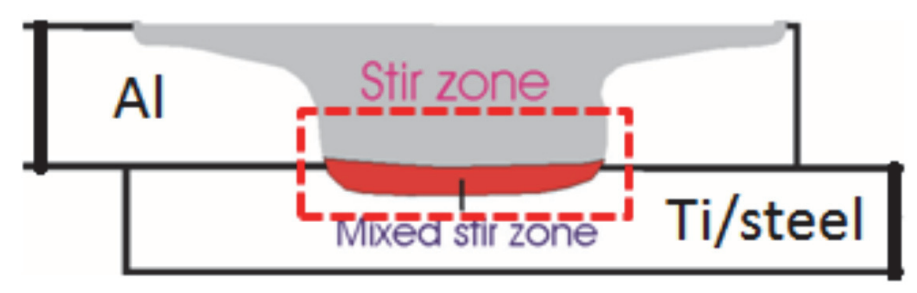

Fig.1. Schematic Illustration of interfacial intermetallics in mixed stir zone 


\section{Experimental procedure}

All FSLW experiments were conducted using a milling machine and thus the mode of FS was displacement control. Schematic illustration of FSLW process has been provided in Fig. 2 shows an actual FSLW experiment. A Lowstir ${ }^{\mathrm{TM}}$ device, which is also shown in Fig. 2, was used in each FSLW experiment to monitor the down-force $(F z)$. This monitoring was necessary when a very precise positioning was needed for the case of dissimilar metals friction stir lap welding. Monitoring of temperature in the joining location was also conducted, by placing $0.2 \mathrm{~mm} \mathrm{~K}$-type thermocouple wires in the lapping location to be FSL welded. Work piece materials were A6060-T5 aluminum alloy plates $6 \mathrm{~mm}$ thick, Titanium and mild steel of $2 \mathrm{~mm}$ thick. Both top and bottom plates were $200 \mathrm{~mm}$ long and $100 \mathrm{~mm}$ wide. Tools were made using H13 tool steel and the left-hand threads of the pins were made with a $1 \mathrm{~mm}$ pitch and a $0.6 \mathrm{~mm}$ actual depth. The diameter of the concave shoulder was $20 \mathrm{~mm}$ for Al-to-steel/Ti FSLW and the pin outside diameter was $6 \mathrm{~mm}$. A tool tilt angle $(\Theta)$ of $3^{\circ}$ was used. In the present experiments, transverse speed (V) ranged from 20 to $540 \mathrm{~mm} / \mathrm{min}$ and rotational speed $(\omega)$ ranged from 600 to $1800 \mathrm{rpm}$. For the work reported here, the penetration depth $D p$ in Fig. 3 was varied for FSLW of Al-to-steel/Ti.

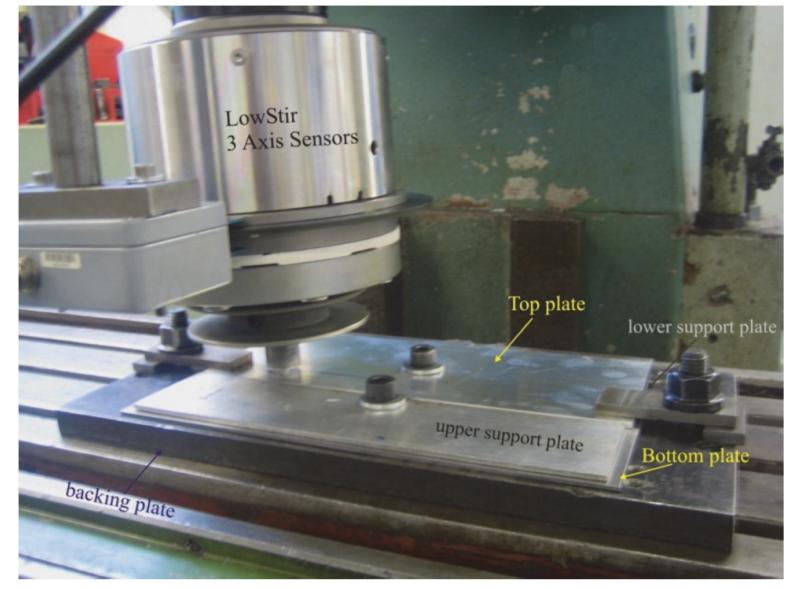

Fig. 2. FSLW using a milling machine with a Lowstir $^{\mathrm{TM}}$ force measuring device

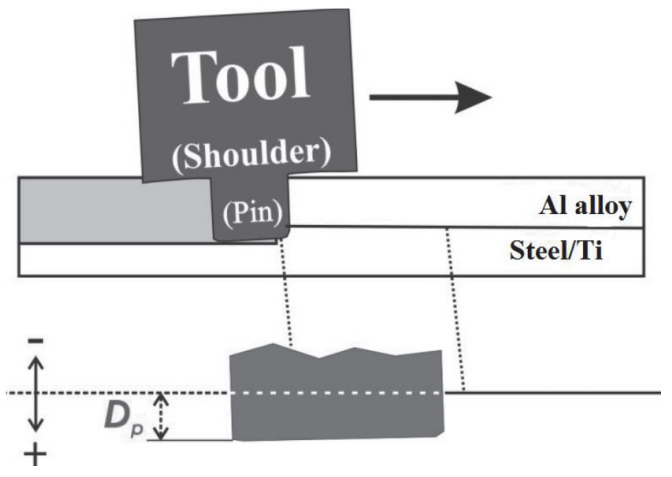

Fig. 3. Schematic illustration of tool positioning during FSLW showing pin penetration depth

For microstructure observation, the welds were cross-sectioned, mounted and polished following the normal metallographic procedure. Microstructure examination was conducted using a normal optical microscope and a Hitachi SU-70 FE SEM with a Thermo Scientific NSS EDS/EBSD system. Tensile-shear testing of FS lap welds has been the major method used for evaluating strength of FSL welds in literature. This test method was adopted in this study. Test samples, $16 \mathrm{~mm}$ wide, perpendicular to the welding direction were machined from the welded plates. Fig. 4 illustrates the positioning of a sample together with supporting pieces. Samples were tested at a constant crosshead displacement rate of $3 \mathrm{~mm} / \mathrm{min}$ using a $50 \mathrm{kN}$ Tinus Olsen tensile machine, with a 50-mm extensometer attached. The strength of a lap sample cannot be expressed using the normal load/area, as the stress distribution along the joint area during tensile-shear test is highly uneven. Instead, maximum failure load in a test divided by the width of the sample, $F m / w s$, is taken as strength.

\section{Results and discussions}

\section{1a Al-Steel Microstructure analysis}

Only two selected samples are shown here to illustrate the importance of interface microstructures and based on this illustration a suggestion of FSLW control for maximum strength can then be made. 
Fig.4 is the first example and a mixed stir zone (MSZ) commonly observed (e.g. Chen \& Nakata (2009), Kimapong \& Watanabe (2005b)) is shown between the top Al plate and the bottom steel plate. The area of MSZ largely corresponds to the area of the pin penetrated in to steel (in a 2D cross section) and this zone is a mixture of $\mathrm{Fe}-\mathrm{Al}$ intermetallic thin pieces embedded in the recrystallized $\alpha$-Fe grains.

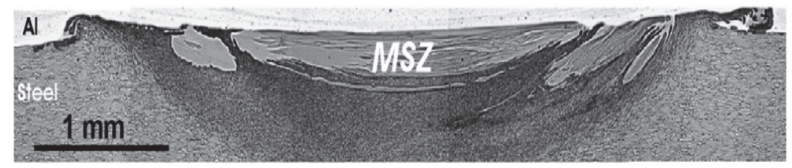

Fig. 4. Cross sectional view of an Al-to-steel weld made with $\omega=1,200 \mathrm{rpm}, v=40 \mathrm{~mm} / \mathrm{min}$ and $D p \approx 0.4 \mathrm{~mm}$ displaying MSZ

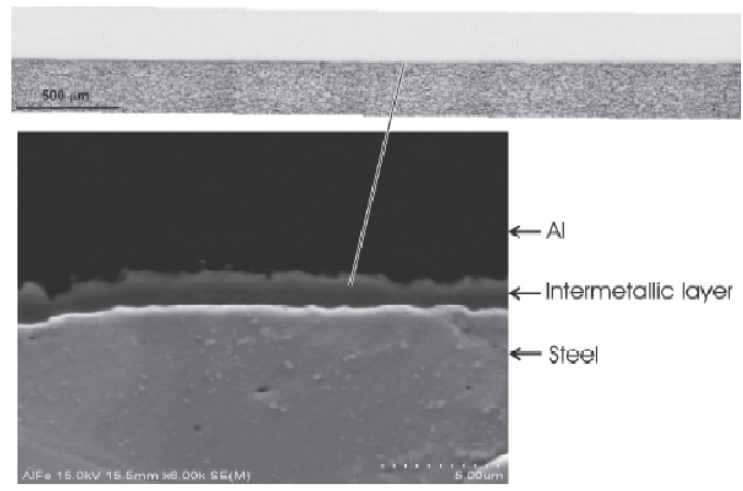

Fig. 5. Cross sectional view of an Al-to-steel weld made with $\omega=1,200 \mathrm{rpm}, v=40 \mathrm{~mm} / \mathrm{min}$ and $D p \approx 0 \mathrm{~mm}$ displaying no MSZ but an interface layer

With a MSZ, a metallurgical bond between $\mathrm{Al}$ and steel is established and thus a slight pin penetration (a slight positive $D p$ value, referring to Fig. 3 ) is commonly believed to be the condition for a good weld strength (e.g. Chen \& Nakata (2009), Kimapong \& Watanabe (2005b)). Naturally, a MSZ cannot form and if $D p<<0$. However, FS tool can be position controlled so that $D p \approx 0$. In this case, although there can still be an absence of MSZ, a thin Fe-Al interface intermetallic layer can form, metallurgically bonding the top and bottom plates together, as demonstrated by an example shown in Fig. 5.

\section{$3.1 \mathrm{~b}$ Al-Steel fracture strength}

Two examples of tensile-tested curves are shown in Fig. 6 for the two different $D_{p}$ conditions. For the penetrated sample, the amount of deformation before final fracture and thus fracture energy is not low. The weld strength at $300 \mathrm{~N} / \mathrm{mm}$ is significantly higher than that of Mg FSL welds $(255 \mathrm{~N} / \mathrm{mm})$ but is considerably lower than that of Al FSL welds $(>430 \mathrm{~N} / \mathrm{mm})$, for $D_{p}=0$. The weld strength at $300 \mathrm{~N} / \mathrm{mm}$ is close to the values of $\sim 315 \mathrm{~N} / \mathrm{mm}$ which is the maximum value for a large group of samples using a slight pin penetration (Chen \& Nakata 2009). In this latter study, when a weld is free of macro-defects the strength equivalent value is close to that maximum value, regardless of what the FS speed condition was. To understand this, an analysis was conducted on a specially tested sample in the present work. As is clearly shown in Fig. 7, cracks propagated in MSZ, likely along the more brittle $\mathrm{Fe}-\mathrm{Al}$ intermetallic pieces and occasionally stopped by the tougher $\alpha$-Fe grains. If this is the common fracture feature and the required fracture strength will then be similar once a MSZ is established, regardless of what the FS condition is so long as the weld is free of defects.

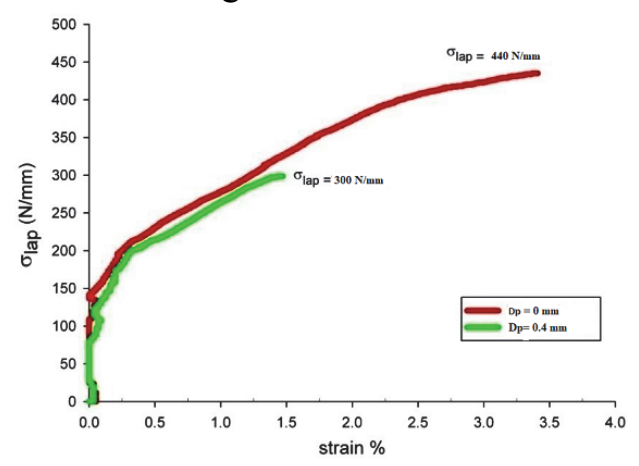

Fig. 6. Tensile-shear curves of two samples of welds made with $\omega=1,200 \mathrm{rpm}, v=40 \mathrm{~mm} / \mathrm{min}$ and $D_{p}$ values as indicated 
When $D p \approx 0$ and an interface layer is established without MSZ, as shown in Fig. 6, fracture strength $(440 \mathrm{~N} / \mathrm{mm})$ is considerably higher than that for the sample with MSZ $(300 \mathrm{~N} / \mathrm{mm})$. The amounts of deformation and fracture energy as indicated by the curve suggest a considerably tougher weld made by the zero $D p$ condition. These are clear by viewing the tested samples in Fig. 8. For the pin penetrated sample $(D p \approx 0.4 \mathrm{~mm})$, the sample having been slightly bent is evident. On the other hand, for the zero $D p$ sample, a large amount of local deformation and bending before the final fracture is clearly the feature. The absence of MSZ in the zero $D p$ sample means a different fracture behavior. The large amounts of deformation and fracture energy for this sample means that the thin interface layer is not brittle under tensile-shear condition. From the present results, it can be suggested that careful positioning control for Al-to-steel FSL welds is a mean for the optimal weld strength to be obtained.

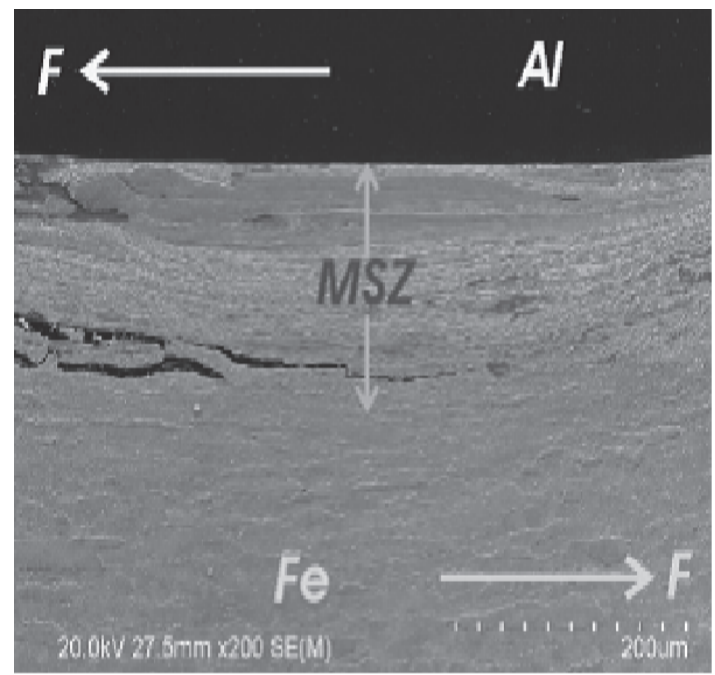

Fig.7. SEM micrograph taken in MSZ region of a weld made with $\omega=1,200 \mathrm{rpm}, v=40 \mathrm{~mm} / \mathrm{min}$ and $D p \approx 0.4 \mathrm{~mm}$ and tested to $270 \mathrm{~N} / \mathrm{mm}\left(\sim 90 F_{m} / w_{s}\right)$

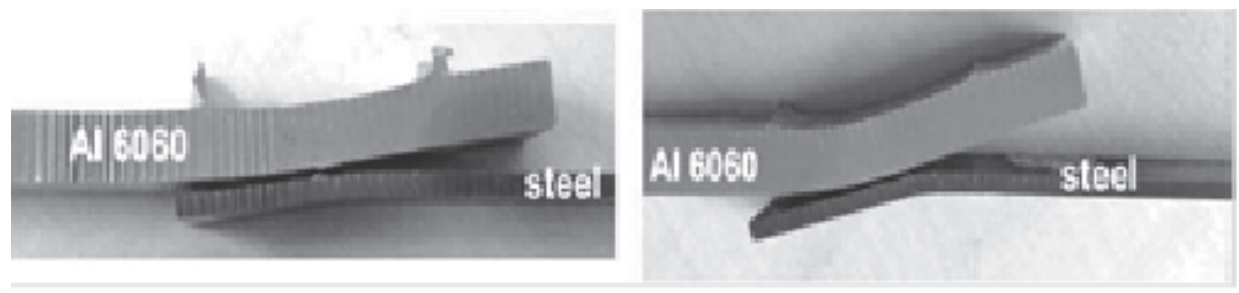

Fig. 8. Tensile-shear tested samples of welds made with $\omega=1,200 \mathrm{rpm}, v=40 \mathrm{~mm} / \mathrm{min}$ and (a) $D p$ $\approx 0.4 \mathrm{~mm}$ and (b) $D p \approx 0 \mathrm{~mm}$

Selected fractographs of tested samples are presented in Fig. 9. The cracks seen in Fig. 9a must be thin as the thickness of the intermetallic layer and normal to the shear direction, thus contributing little to the shearing process resulting in ductile fracture. A significant portion of the fracture surface as shown in Fig 9b displayed brittle fracture feature. It is likely that cracking propagated along (parallel to) the thin intermetallic layers in the penetrated laminate region during testing.

\section{2a Al-Ti microstructure analysis}

Microstructure corresponding to the sample 1 with $D p \approx 0$ pin penetration is shown in Fig. 10a with low magnification SEM micrograph, however a very thin continuous intermetallic layer (with average thickness of approximately $\sim 300 \mathrm{~nm}$ ) can be seen in the SEM micrograph of interfacial region Fig. 10b. It should be noted that characterization of intermetallic layer was not possible in this study 
due the very thin thickness of interfacial intermetallic layer. However, formation of $\mathrm{TiAl}_{3}$ intermetallic compound in Al-Ti FSL welds has been reported in literature (Chen \& Nakata, 2009). High $\sigma_{\text {Lap }}$ value $(745 \mathrm{~N} / \mathrm{mm})$ obtained for no pin penetration tested sample indicates that this very thin intermetallic layer created a strong continuous metallurgical bond at Al-Ti interface.

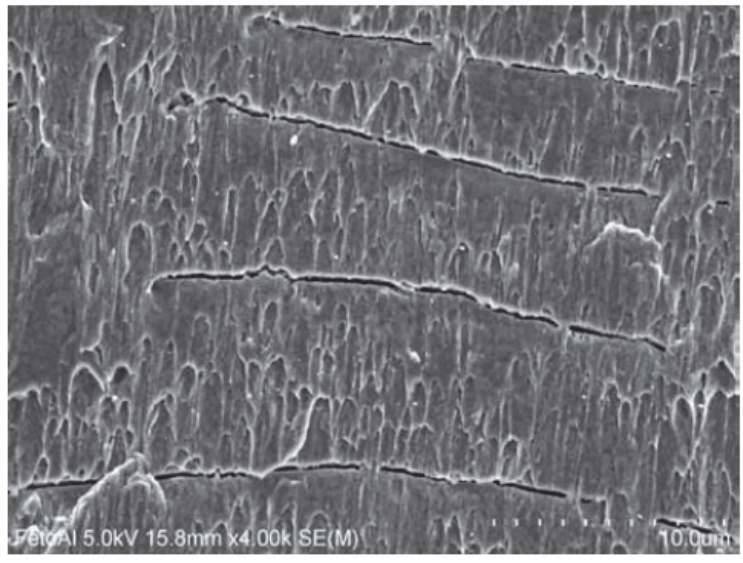

(a)

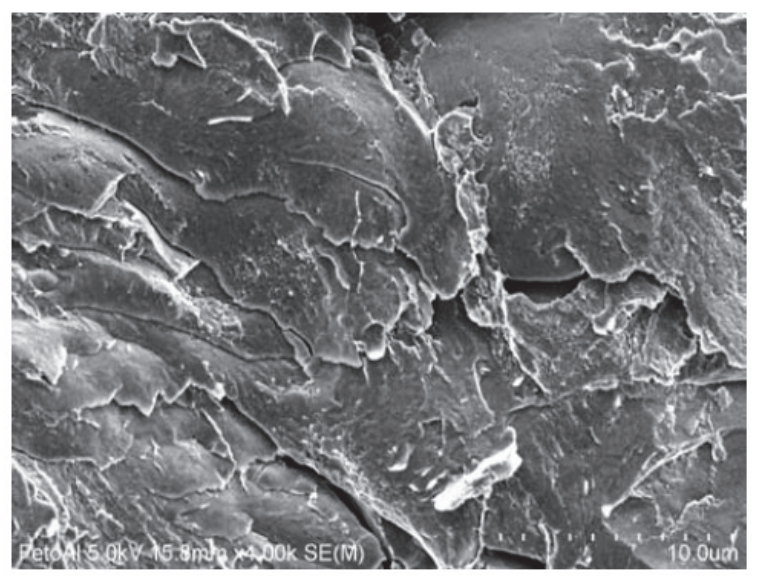

(b)

Fig. 9. Fracture surfaces of the tensile-shear tested samples (a) ductile and (b) brittle fracture
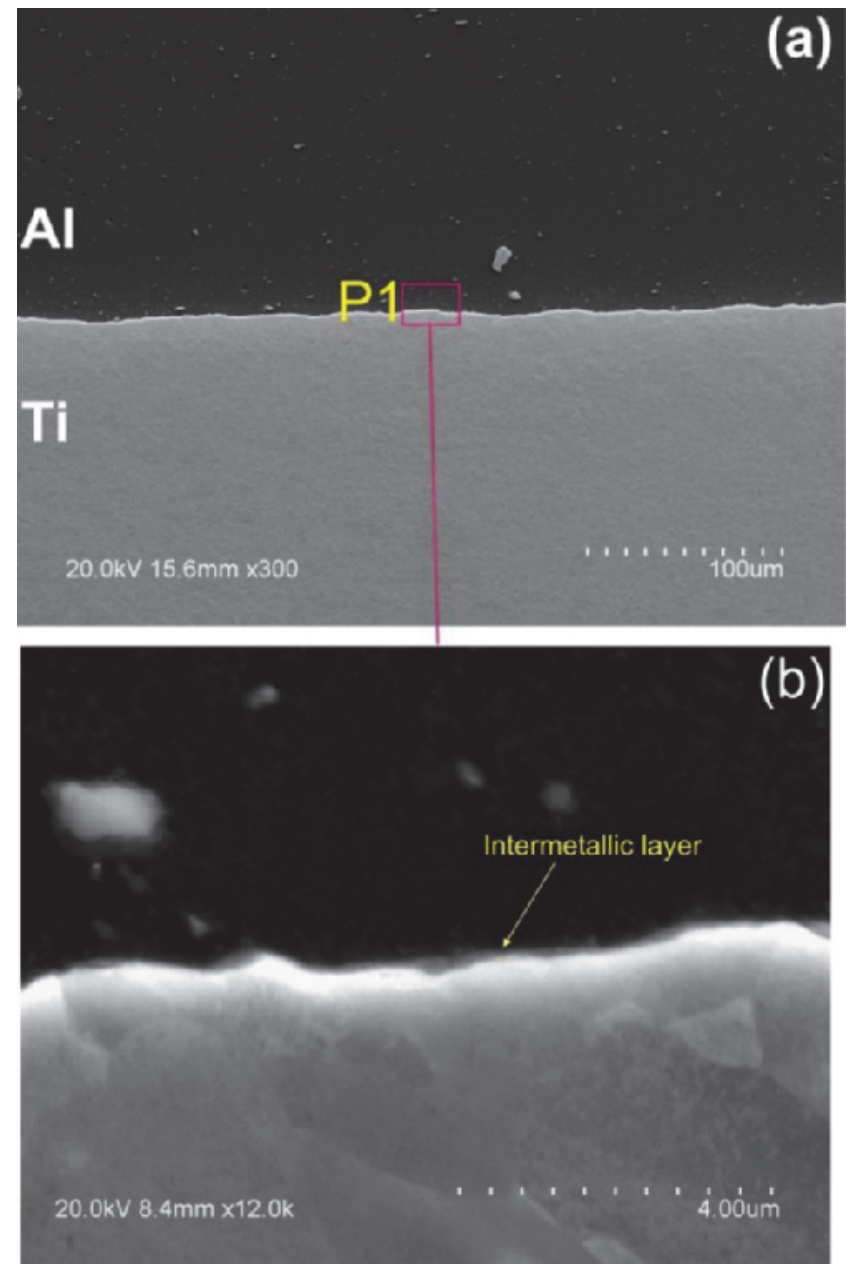

Fig.10. Microstructure of no penetration sample as (a) low magnification SEM micrograph (b) high magnification SEM micrograph showing a very thin interfacial intermetallic layer 
For sample 2, significant pin penetration took place $(D p \approx 0.4 \mathrm{~mm})$ as seen in Fig. 11 . Thus, an irregular laminate of titanium and Ti-Al intermetallic layers formed in penetrated region (Fig.11b-c), which is similar to the observations made in literature (Chen \& Nakata 2009), when the pin penetrating condition used. Also, many micro-cracks formed in the penetrated region (Fig.11b-c) which is likely due to strain caused by considerable difference in thermal expansion coefficients of titanium and of aluminum. Furthermore, the pin penetration and insufficient material flow of titanium alloy during FSLW resulted in formation of many voids in penetrated region (Fig.11d). Presence of micro-cracks and void in the weld, resulted in relatively low $\sigma_{\text {Lap }}$ value $(350 \mathrm{~N} / \mathrm{mm})$ for the sample 2.

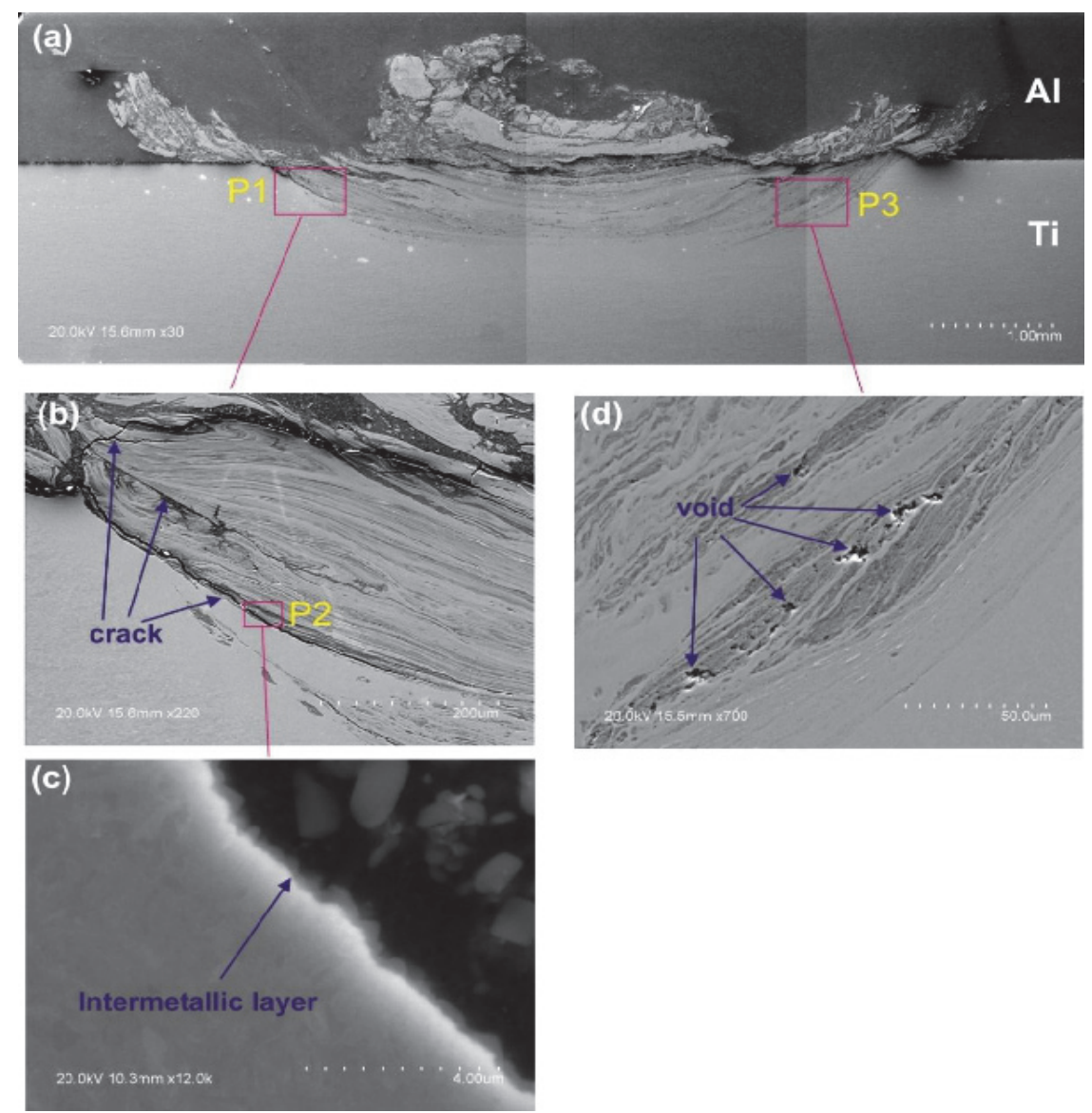

Fig. 11. Microstructure of sample 2 (a) macrograph (b) higher magnification micrograph of area $P 1$ in Figure 11a showing the cracks formed in the penetrated region (c) higher magnification micrograph of area P2 in Fig. 11b showing intermetallic layers in the penetrated region (d) higher magnification micrograph of area P3 in Fig. 11a

\section{2b Al-Ti fracture strength}

During tensile shear testing, sample1 fractured along the Al-Ti interface (Fig. 12a) and Al 6060-T5 plate rotated considerably before failure. The bright portion seen on fracture surface of titanium side of tested sample (Fig. 12b) indicates that fracture surface is covered by the smeared residue of aluminum. Closer view of fracture surface (Fig. $12 \mathrm{c}$-e) clearly shows that a ductile fracture is dominant with plastic (shear) deformation preceding failure in aluminum adjacent to and on top of the interfacial intermetallic layer. Also, EDS map analysis of fracture surface (Fig12 f-g) clearly reveals the presence of smeared aluminum (heavily deformed) on top of fracture surface. 


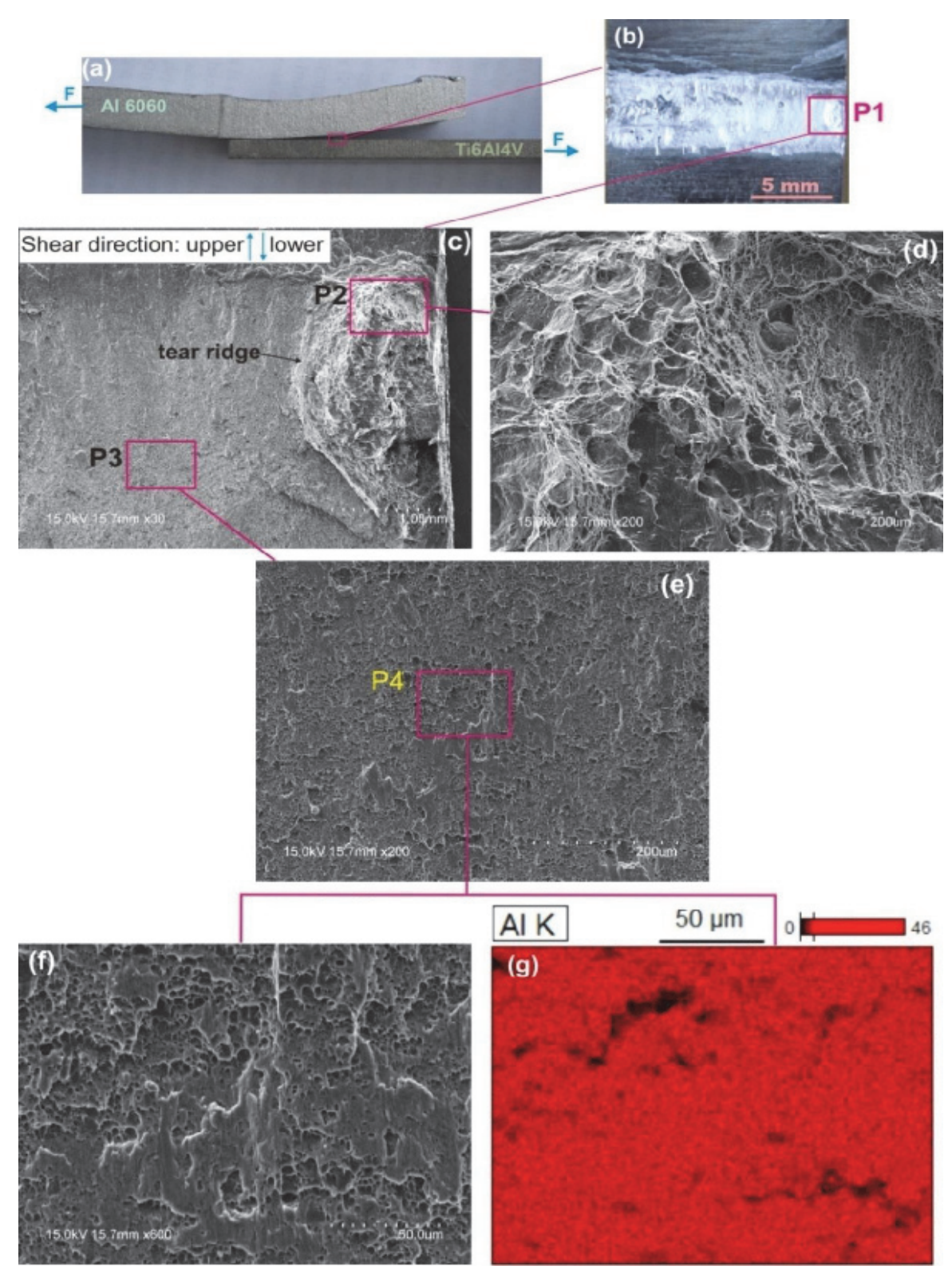

Fig.12. Fracture surface of tested sample 1: (a) fractured sample (b) image of titanium side of tested sample (c) SEM micrograph of area P1 in Figure 12a showing aluminum tear ridges adhering to the titanium surface (d) SEM micrograph of area P2 in Fig. 12c showing ductile dimples associated with fracturing in aluminum (e) SEM micrograph of area P3 in Figure 12c showing the heavily deformed aluminum on top of the intermetallic layer (f) SEM micrograph of area P4 in Fig. 12e with associated (g) EDS map of Al

The aluminum macro tear ridge adhered to the fracture surface (Figs.12 c-d) indicates the strong cohesion at the interfaces of Ti/intermetallic/Al so that fracture occurred at aluminum side. Moreover, no intermetallic cracking (underneath the smeared aluminum) can be observed on fracture surface, these results suggest that the interface structure for sample 1 (with a single continuous intermetallic layer) is highly shear fracture. Fig. 13 shows the sample 2 with $D p \approx 0.4 \mathrm{~mm}$, tensile shear tested to fracture. The fractographs in Fig. $13 \mathrm{c}$-d clearly shows that significant portion of the fracture surface is of brittle failure. The flake-like features formed on fracture surface suggest that cracking propagated along (parallel to) the intermetallic layers inside the laminate (penetrated) region. Therefore, smaller amount of Al 6060-T5 rotation occurred before failure (Fig. 13a), compared to tested sample 1 (Fig. $12 \mathrm{a})$, indicating smaller plastic deformation during testing. 


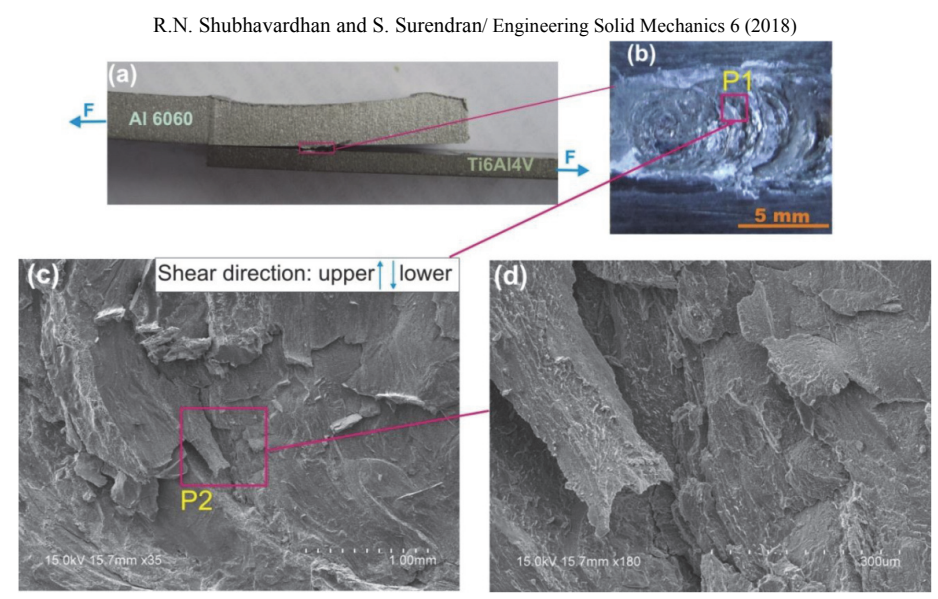

Fig. 13. Fracture surface of tested sample 2: (a) fractured sample (b) image of titanium side of tested sample (c) SEM micrograph of area P1 in Fig. 13b displaying brittle fracture features (b) higher magnification micrograph of area $\mathrm{P} 2$ in Fig.13c

The fracture surface characteristics of sample 2 are very similar to those observed on fracture surface of Al-Steel weld, when the pin penetrated to steel. These results suggest that the pin penetrating condition in FSLW of either Al-Steel or Al-Ti results in interface microstructures in which cracking tends to propagate along (parallel to) the irregular intermetallic layers inside the penetrated region. Furthermore, microcracks formed in the penetrated region, in FSL welds of either Al-Steel or Al-Ti, can act as favorable cracking initiation source (under loading) and facilitate the fracturing with lower $\sigma_{\text {lap. }}$

\section{Conclusions}

For Al-Steel FSL welds, joint strength was found to be very sensitive to pin positioning during FSLW. When the bottom of pin reached the steel surface without penetrating $\left(D_{p} \approx 0 \mathrm{~mm}\right)$ during FSLW, a single continuous intermetallic layer formed along the interface; and thus, continuous metallurgical bonding established. The joint produced by this non pin penetrating condition (with a single continuous intermetallic at interface) displayed a high $\sigma_{\text {Lap }}$ value $(440 \mathrm{~N} / \mathrm{mm})$ which was $\sim 42 \%$ increase in $\sigma_{\text {Lap }}$ in comparison to the case of pin penetrating condition $\left(D_{p} \approx 0.4 \mathrm{~mm}\right) \sigma_{\text {Lap }} 300 \mathrm{~N} / \mathrm{mm}$ (with the mixed interface region). For Al-Ti FSL welds, the pin positioning during FSLW was also found to be the major parameter affecting $\sigma_{\text {Lap }}$ of welds, similar to that of Al-Steel FSLW. For the sample made using non-pin penetrating condition of $D_{p} \approx 0 \mathrm{~mm}$, a thin continuous intermetallic layer formed along the joint interface resulting in a strong metallurgical bonding with high $\sigma_{\text {Lap }}$ value (745 $\mathrm{N} / \mathrm{mm}$ ) during testing. However the pin penetrating condition had detrimental effect on joint strength $(350 \mathrm{~N} / \mathrm{mm})$ due to formation of voids and micro-cracks in the penetrated region.

\section{References}

Abdollah-Zadeh, A., Saeid, T., \& Sazgari, B. (2008). Microstructural and mechanical properties of friction stir welded aluminum/copper lap joints. Journal of alloys and Compounds, 460(1), 535-538.

Akbari, M., Aliha, M. R. M., Keshavarz, S. M. E., \& Bonyadi, A. (2016). Effect of tool parameters on mechanical properties, temperature, and force generation during FSW. Proceedings of the Institution of Mechanical Engineers, Part L: Journal of Materials: Design and Applications, 1464420716681591.

Aliha, M. R. M., Shahheidari, M., Bisadi, M., Akbari, M., \& Hossain, S. (2016). Mechanical and metallurgical properties of dissimilar AA6061-T6 and AA7277-T6 joint made by FSW technique. The International Journal of Advanced Manufacturing Technology, 86(9-12), 2551-2565.

Aonuma, M., \& Nakata, K. (2011). Dissimilar metal joining of 2024 and 7075 aluminium alloys to titanium alloys by friction stir welding. Materials Transactions, 52(5), 948-952.

Chen, S., Li, L., Chen, Y., Dai, J., \& Huang, J. (2011). Improving interfacial reaction nonhomogeneity during laser welding-brazing aluminum to titanium. Materials \& Design, 32(8), 4408-4416. 
Chen, Y. C., \& Nakata, K. (2008). Effect of the surface state of steel on the microstructure and mechanical properties of dissimilar metal lap joints of aluminum and steel by friction stir welding. Metallurgical and Materials Transactions A, 39(8), 1985-1992.

Chen, Y. C., \& Nakata, K. (2009). Microstructural characterization and mechanical properties in friction stir welding of aluminum and titanium dissimilar alloys. Materials \& Design, 30(3), 469-474.

Chen, Y. C., Komazaki, T., Kim, Y. G., Tsumura, T., \& Nakata, K. (2008). Interface microstructure study of friction stir lap joint of AC4C cast aluminum alloy and zinc-coated steel. Materials Chemistry and Physics, 111(2), 375-380.

Chen, Y. H., Quan, N. I., \& Ke, L. M. (2012). Interface characteristic of friction stir welding lap joints of Ti/Al dissimilar alloys. Transactions of Nonferrous Metals Society of China, 22(2), 299-304.

Coelho, R. S., Kostka, A., Sheikhi, S., dos Santos, J., \& Pyzalla, A. R. (2008). Microstructure and Mechanical Properties of an AA6181-T4 Aluminium Alloy to HC340LA High Strength Steel Friction Stir Overlap Weld. Advanced Engineering Materials, 10(10), 961-972.

Elrefaey, A., Gouda, M., Takahashi, M., \& Ikeuchi, K. (2005). Characterization of aluminum/steel lap joint by friction stir welding. Journal of Materials Engineering and Performance, 14(1), 10-17.

Elrefaey, A., Gouda, M., Takahashi, M., \& Ikeuchi, K. (2005). Characterization of aluminum/steel lap joint by friction stir welding. Journal of Materials Engineering and Performance, 14(1), 10-17.

Fuji, A., Ikeuchi, K., Kimura, M., Satoh, Y. S., Kokawa, H., \& 冨士明良. (2001). In-situ Observation of Interlayer Growth during Post-weld Heat Treatment in Friction-welded Joint of Titanium and Aluminum.

Fuji, A., Ikeuchi, K., Sato, Y. S., \& Kokawa, H. (2004). Interlayer growth at interfaces of Ti/Al-1\% Mn, Ti/Al4. $6 \% \mathrm{Mg}$ and Ti/pure $\mathrm{Al}$ friction weld joints by post-weld heat treatment. Science and technology of welding and joining, 9(6), 507-512.

Fuji, A., Kimura, M., North, T. H., Ameyama, K., \& Aki, M. (1997). Mechanical properties of titanium-5083 aluminium alloy friction joints. Materials Science and Technology, 13(8), 673-678.

Jiang, W. H., \& Kovacevic, R. (2004). Feasibility study of friction stir welding of 6061-T6 aluminium alloy with AISI 1018 steel. Proceedings of the Institution of Mechanical Engineers, Part B: Journal of Engineering Manufacture, 218(10), 1323-1331.

Kimapong, K., \& Watanabe, T. (2005a). Lap joint of A5083 aluminum alloy and SS400 steel by friction stir welding. Materials transactions, 46(4), 835-841.

Kimapong, K., \& Watanabe, T. (2005b). Effect of welding process parameters on mechanical property of FSW lap joint between aluminum alloy and steel. Materials transactions, 46(10), 2211-2217.

Liedl, G., Bielak, R., Ivanova, J., Enzinger, N., Figner, G., Bruckner, J., ... \& Hampel, S. (2011). Joining of aluminum and steel in car body manufacturing. Physics Procedia, 12, 150-156.

Mohammad Aliha, M. R., Fotouhi, Y., \& Berto, F. (2017). Experimental notched fracture resistance study for the interface of $\mathrm{Al}-\mathrm{Cu}$ bimetal joints welded by friction stir welding.

Proceedings of the Institution of Mechanical Engineers, Part B: Journal of Engineering Manufacture, 0954405416688935.

Movahedi, M., Kokabi, A. H., Reihani, S. S., \& Najafi, H. (2011). Mechanical and microstructural characterization of Al-5083/St-12 lap joints made by friction stir welding. Procedia Engineering, 10, 32973303.

Robertson, I. M., \& Schaffer, G. B. (2010). Review of densification of titanium based powder systems in press and sinter processing. Powder metallurgy, 53(2), 146-162.

Taban, E., Gould, J. E., \& Lippold, J. C. (2010). Dissimilar friction welding of 6061-T6 aluminum and AISI 1018 steel: Properties and microstructural characterization. Materials \& design, 31(5), 2305-2311.

Vaidya, W. V., Horstmann, M., Ventzke, V., Petrovski, B., Koçak, M., Kocik, R., \& Tempus, G. (2010). Improving interfacial properties of a laser beam welded dissimilar joint of aluminium AA6056 and titanium Ti6A14V for aeronautical applications. Journal of materials science, 45(22), 6242-6254.

Wilden, J., \& Bergmann, J. P. (2004). Manufacturing of titanium/aluminium and titanium/steel joints by means of diffusion welding. Welding and Cutting, 56(5), 285-290.

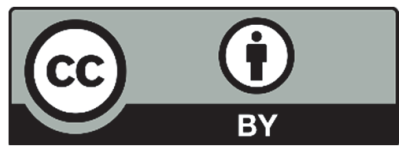

(C) 2018 by the authors; licensee Growing Science, Canada. This is an open access article distributed under the terms and conditions of the Creative Commons Attribution (CC-BY) license (http://creativecommons.org/licenses/by/4.0/). 